\title{
Evidence of a connotative dimension in short-term memory as a function of retention interval
}

\author{
M. T. TURVEY ${ }^{1}$ \\ OHIO STATE UNIVERSITY
}

The possibility of a connotative dimension operating in $S T M$ was investigated by the use of an RIP design. Connotative difference between items did not facilitate recall at a retention interval of $12 \mathrm{sec}$ but was found to be significantly effective at a retention interval of $24 \mathrm{sec}$. The results were discussed in terms of the notion that the manifestation of higher-order codes is time dependent.

In the analysis of the short-term memory (STM) mechanism, it is assumed that certain codes are operative in the storing of presented information. Search for these codes has provided substantial evidence of an acoustic dimension operating (Conrad, 1964; Wickelgren, 1966) but only sparse evidence of the presence of other possible codes of somewhat higher-order genre such as meaningfulness (Dale \& Gregory, 1966; Baddeley, 1966). A recent study by Clarke \& Wickens (1966) indicated that a connotative dimension might be present in STM. The present experiments were conducted to assess this possibility.

\section{EXPERIMENT 1}

Method

The experimental design employed has been referred to by Kopenaal \& O'Hara (1962) as an RIP design because of its confounding of retroactive and proactive interference. This design was used to allow for an assessment of retroactive effects as indicated by observation of Trial 1 , and overall interference magnitude as indicated by consideration across trials. Four trials were administered. On each trial two word diads were presented. The first diad was presented on a red background, the second diad appeared against a green background. The words constituting a diad were chosen either from the positive or negative end of the evaluative dimension of the Semantic Differential (Osgood, Suci, \& Tannenbaum, 1957). Thus diads were classified as evaluative positive $(E+)$ or evaluative negative (E-). The words were selected on the basis of their lying at the extreme ends of the evaluative dimension and on their being relatively neutral in the other dimensions. The words were drawn from the pool classified by Heise (1965). A trial was composed of the following events, presented in terms of a sequence of slides delivered by a Kodak Carousel projector and controlled by a tape timer: (a) ready signal of 2 sec duration; (b) red diad of 2 sec duration, read aloud by $S$; (c) green diad of 2 sec duration, read aloud by $S$; (d) three-digit number presented throughout the retention interval of 12 sec. $S$ counted backwards aloud from this number in threes to the beat of a metronome set at 60 beats per min. This constituted the interpolated task. (e) recall cue presented on a red background signalling recall of the red diad. $S$ 's recall was recorded by $E$. $S$ was informed in the preexperiment instructions that he might be asked to recall either the red or the green slide.

Sixty Ss were drawn from the Ohio State University subject pool composed of undergraduates partjcipating in the introductory psychology program. Ss were allotted randomly to one of four conditions. These conditions were designated as $\mathrm{E}_{+} / \mathrm{E}_{+}, \mathrm{E}-/ \mathrm{E}-, \mathrm{E}+/$ $\mathrm{E}-$, and $\mathrm{E}-\mathrm{E}+$, representing the nature of the first diad (i.e., red) and the second diad (i.e., green) as presented on each trial. The first two conditions, therefore, were the controls for the latter two conditions. The design thus entailed that the diads to be recalled were the same in both the experimental and control situations, the difference between the situations being in terms of whether or not the second diad was from the same or opposite end of the evaluative dimension.

Resul ts

Each $S$ was scored in terms of how many words were correctly recalled. A t test revealed no significant difference between the control and experimental groups with respect to the overall recall data $(p>.05)$ or with respect to the recall data from Trial $1(p>.05)$.

\section{EXPERIMENT 2}

The results of Experiment 1 do not by necessity rule out the possibility of a connotative dimension. In a recent theoretical paper, Peterson (1966) presented the notion that in STM the presence of a cogent short-term component may obscure the manifestation of an alternate, longer-term component. Therefore the posslbility remains that a connotative dimension might only be manifest at longer retention intervals, by which time, supposedly, the hegemony of the short-term component has been reduced. A second experiment was conducted which duplicated the first in all details except for the application of a $24 \mathrm{sec}$ retention interval as opposed to the $12 \mathrm{sec}$ interval used in Experiment 1. A new sample of 60 Ss was drawn from the same population. 


\section{Results and Discussion}

A $t$ test on the overall recall data revealed a significant difference between the experimental and control groups $(t=2.25, d f=58, p<.025)$. A $t$ test on the Trial 1 data failed to reach significance at the .05 level $(t=1.50$, df $=58, .05<p<.10)$. A more specific analysis of the Trial 1 data revealed that the difference between the $\mathrm{E}+\mathrm{E}$ - experimental condition and the $E_{+} / E_{+}$control condition was, however, significant $(t=2.64, \mathrm{df}=29, \mathrm{p}<.01)$. Therefore, at the extended retention interval of $24 \mathrm{sec}$ there is evidence of facilitated recall as a function of connotative difference in the presented information.

The import of these data is that they indicate the need for a more parametric probing of the retention space in STM experiments, particularly when the experimental concern is with the teasing out of modes of representation. Furthermore, they lend credence to Peterson's (1966) argument that the efficacy and manifestation of components of storage are time dependent. It is noteworthy that the contention that STM engages an acoustic code is based primarily upon experiments employing almost immediate recall rather than delayed recall. A recent study by Conrad (1967) demonstrated that the phonemic mode of representation in STM decreases over the retention period. In this investigation Conrad observed that error production at an extended retention interval $(7.5 \mathrm{sec})$ was tending toward randomness, whereas error production at a shorter interval $(2.4 \mathrm{sec})$ was highly systematically related to the presented information along the phonemic dimension.

One might suspect, therefore, that the acoustic code is, in the early stages of retention, the most efficacious, and tends to obscure the presence of alternate codes (e.g., connotative). These alternate codes only become observable at a later phase, subsequent to the reduction in dominance of the phonemic representation.

References

BADDELEY, A. D. Short-term memory for word sequences as a function of acoustic, semantic and formal similarity. Quart. J. exp. Psychol, 1966, 18, 362-365.

CLARKE, S., \& WICKENS, D. D. Proactive inhibition and the semantic differential in short-term memory. Paper read at Midwestern Psychological Association Meeting. Chicago, 1966.

CONRAD, R. Acoustic confusions in immediate memory. Brit. $J$. Psychol, 1964, 55, 75-84.

CONRAD, R. Interference or decay over short retention intervals? $J$. verbal Learn. lerbal Behav., 1967, 6, 49-54.

DALE, H. C. A., \& GREGORY, M. Evidence of semantic coding in shortterm memory. Psychon. Sci, 1966, 5, 75-76.

HEISE, D. R. Semantic differential profiles for 1,000 most frequent English words. Psychol. Monogr., 1965 (Whole No. 601).

KOPENAAL. R. J., \& O'HARA, G. N. The combined effect of retroaction and proaction. Canad. J. Psychol., 1962, 16, 96-105.

OSGOOD, C. E., SUCI, G. J., \& TANNENBAUM, P. H. The measurement of meaning. Urbana: University of Illinois Press, 1957.

PETERSON, L. R. Short-term verbal memory and learning. Psychol. Rev., 1966, 3, 193-207.

WICKEIGREN, W. A. Plionemic similarity and interference in shortterm memory for single letters. J. exp. Psychol., 1966, 71, 396-404. Note

1. Now at the University of Connecticut. 